\title{
Prevalence of Chagas heart disease in dilated cardiomyopathy
}

\section{Prevalencia de cardiopatía chagásica en la miocardiopatía dilatada}

\author{
Héctor González-Zambrano ${ }^{*}$, Gerardo Amaya-Tapia², María C. Franco-Ramos³, and \\ Oscar J. López León-Murguía ${ }^{4}$
}

${ }^{1}$ Servicio de Cardiología; ${ }^{2}$ Servicio de Infectología. Hospital General de Occidente, Secretaria de Salud Jalisco, Zapopan; ${ }^{3}$ Laboratorio estatal de salud pública del Estado de Jalisco, Zapopan; ${ }^{4}$ Departamento de Ciencias Médicas, Centro Universitario de la Costa, Universidad de Guadalajara, Puerto Vallarta. Jalisco, México

\begin{abstract}
Objectives: The main objective is to determine the prevalence of American trypanosomiasis in patients with dilated cardiomyopathy in a tertiary hospital in western Mexico. Methods: From January 1991 to February 2016, 387 consecutive patients with a confirmed diagnosis of dilated cardiomyopathy were included in the study. Cases with ventricular dilatation secondary to ischemic heart disease, valvular heart disease, hypertension, lung disease, pericardial disease, or congenital heart disease were excluded from the study. Diagnosis was made detecting antibodies against Trypanosoma cruzi with two different methods or parasite in blood. Results: Were included 387 patients with dilated cardiomyopathy, Chagas cardiomyopathy was confirmed in 6.9\%, two patients in the acute phase (in one, suspected transfusion transmission was detected). Most patients were born in rural areas. About $96.2 \%$ showed congestive heart failure, only one patient with apical left ventricular aneurysm manifested palpitations. About $66 \%$ with right bundle branch block, left anterior fascicular block, or the association of both, in $14.8 \%$, non-sustained ventricular tachycardia was found. Conclusions: Chagas cardiomyopathy is common in México, mainly in people who were born or lived during childhood in rural areas. It is a common cause of heart failure. Chagas' heart disease should be suspected in patients receiving a blood transfusion, even without another epidemiological history.
\end{abstract}

Key words: Chagas heart disease. Dilated cardiomyopathy. American trypanosomiasis.

\section{Resumen}

Objetivo: El objetivo principal del estudio es conocer la prevalencia de tripanosomiasis americana en pacientes con cardiomiopatía dilatada, en un hospital de concentración en el occidente de México. Métodos: Desde enero de 1991 a febrero de 2016 se incluyeron 387 pacientes consecutivos con diagnóstico de cardiomiopatía dilatada, se excluyeron los casos con dilatación ventricular secundaria a cardiopatía isquémica, valvulopatías, hipertensión arterial sistémica, enfermedad pulmonar, enfermedad pericárdica o cardiopatías congénitas. El diagnóstico se realizó mediante la detección de anticuerpos anti-tripanosoma cruzi con 2 métodos positivos diferentes o con la detección del parásito en sangre. Resultados: Se incluyeron 387 paciente con cardiomiopatía dilatada, en el 6.9\% se confirmó cardiopatía chagásica; dos pacientes en fase aguda (uno con sospecha de transmisión transfusional). La mayoría de los pacientes provenían de zonas rurales. El 96.2\% de los casos presentó insuficiencia cardiaca congestiva, un paciente con aneurisma apical del ventrículo izquierdo solo

\section{Correspondence:}

*Héctor González-Zambrano

E-mail: hector.gz@ hotmail.com
Date of reception: 06-02-2020

Date of acceptance: 12-06-2020

DOI: 10.24875/ACM.20000042
Available online: $20-10-2020$

Arch Cardiol Mex. 2021;91(1):50-57 www.archivoscardiologia.com 1405-9940 / @ 2020 Instituto Nacional de Cardiología Ignacio Chávez. Published by Permanyer. This is an open access article under the CC BY-NC-ND license (http://creativecommons.org/licenses/by-nc-nd/4.0/). 
manifestó palpitaciones. El 66\% presentó bloqueo de la rama derecha del haz de His, hemibloqueo anterior izquierdo o la asociación de ambos, en el $14.8 \%$ se encontró taquicardia ventricular no sostenida. Conclusiones: La cardiopatía chagásica es frecuente en nuestro medio, principalmente en personas que nacieron o vivieron durante la infancia en áreas rurales. Es causa común de insuficiencia cardiaca. La cardiomiopatía chagásica debe sospecharse en pacientes que reciben transfusión sanguínea, incluso sin otros antecedentes epidemiológicos

Palabras clave: Cardiopatía chagásica. Cardiomiopatía dilatada. Tripanosomiasis americana.

\section{Introduction}

Chagas disease or American trypanosomiasis is a zoonosis transmitted to man mainly by a triatomine vector disseminated in America from the southern United States to southern Chile and Argentina. It is a major public health problem in Latin America and it is currently estimated that about 6 million people are affected by the disease ${ }^{1}$ and observes 30,000 vector cases/year, 9000 infected births, and generally produces 14,000 deaths/year. Vector is a wild nocturnal hematophagous insect, which can be intradomiciliary in areas of extreme poverty. Nineteen of the 31 species of Triatoma recognized in Mexico have the potential to invade rural dwellings and in all of them, the particularity of being infected by $T$. cruzi has been found ${ }^{2}$. In Mexico, the Triatoma species important for the vector transmission of the disease are two intradomiciliary: $T$. barberi and T. dimidiata and 11 peridomiciliary the most frequent; Meccus pallidipennis ${ }^{3}$. The transfusion route is the second transmission mechanism in order of frequency 4 . Cardiological and digestive affectation causes high morbidity and mortality, with frequent hospitalizations and even the necessity of surgical procedures, which means an important economic cost. The disease was described in Mexico by Luis Mazotti in $1940^{5}$, but it was not until 25 years later when the first two confirmed cases of Chagas cardiomyopathy (CC) were described ${ }^{6}$. In the national seroepidemiological survey carried out from 1987 to 1989, was reported a seroprevalence of $1.6 \%$ in the Mexican population 7 . According to estimates from the World Health Organization, Mexico is currently considered within the countries with a seroprevalence that ranges from 0.1 to $0.9 \%{ }^{8}$. In large studies in México, the prevalence of $C C$ in patients with dilated cardiomyopathy (DC) is from 8 to $40 \% \%^{9,10}$.

Even though the main transmission route is vectorial, the increasing migration of the Latin American population to countries of North America and Europe has generated great public health uncertainty, given the great possibility of transmitting the disease to these nations through non-vectorial transmission, mainly by blood transfusion ${ }^{11}$. Post-transfusion transmission due to globalization affects not only North America and Europe but also the entire world (reporting cases even in Asia and Oceania) $)^{12}$. The main objective was to determine the prevalence of $C C$ in patients with $D C$, who were recruited prospectively in a tertiary hospital in western Mexico for 25 years.

\section{Methods}

In an observational and prospective study, from February 1991 until January 2016, all cases referred to the cardiology department with $\mathrm{DC}$ regardless of age at the time of diagnosis were included in the study. Those with ventricular dilation secondary to ischemic heart disease, valvular disease, systemic arterial hypertension, pericardial disease, or congenital heart disease were excluded from the study. In all cases, a detailed clinical history was made, 12-lead electrocardiogram, chest X-ray, transthoracic echocardiogram, 24-h Holter, and laboratory tests that included: blood count, blood chemistry, serum electrolytes, liver functional tests, thyroid profile, and urinalysis. Anti-Trypanosoma cruzi antibodies were determined by at least two of the following methods: indirect immunofluorescence assay, indirect hemagglutination assay, or enzyme-linked immunosorbent assay (ELISA). In cases with suspected acute stage of the disease, the blood parasite was searched directly with Strout method ${ }^{13}$. Serological and parasitological assays were conducted in the public health laboratory of Jalisco state. According to the international standard proposed by an expert committee of the World Health Organization ${ }^{14,15}$, patient with positive antibodies to $T$. cruzi was diagnosed as having CC through two different positive tests; indirect immunofluorescence assay or indirect hemagglutination assay (with dilution equal to or greater than 1:32) and/or positive ELISA, as well as, patient with trypanosomes in blood with the described method. Place of birth and current residence, recognition of Triatoma, current housing type, and in childhood were investigated, as well as chagoma (T. cruzi skin abscess) or Romaña sign (unilateral conjunctivitis and painless swelling of the upper and lower 


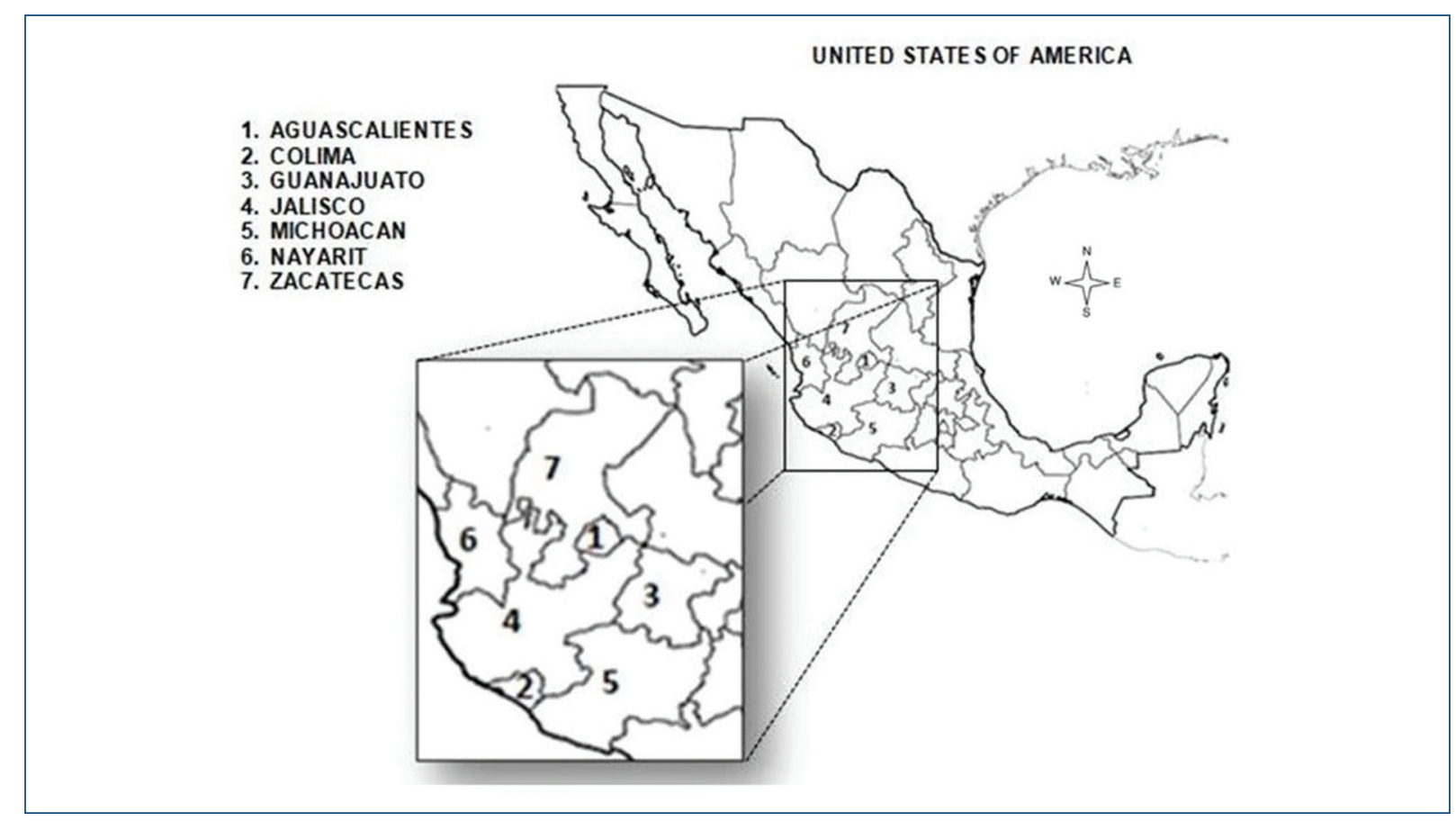

Figure 1. States of the country where patients with chagasic heart disease come from.

eyelids). Contrast radiography studies were performed to investigate the dilation of the digestive tract in patients with chronic CC.

\section{Statistical analysis}

Qualitative variables are expressed as frequency distribution and quantitative variables as an average \pm standard deviation. We analyzed some demographic characteristics and lifestyles related to CC risk; these included ages, sex, and type of housing, if they know the vector, if the vector has bitten them and if they have presented a primary infection. For the comparison of DC groups between seropositive and seronegative to $\mathrm{CC}$, a univariate analysis was performed. Continuous variables using the Student's t-test and categorical variables using the Chi-square test or Fisher's exact test, as appropriate. A value $p \leq 0.05$ was considered significant. The data were processed and analyzed with the program Primer of Biostatistics (Stanton A. Glantz), seventh edition.

\section{Results}

Three hundred eighty-seven patients were included, $27(6.9 \%)$ met the laboratory criteria described to perform the diagnosis of CC. Cases come from states of western Mexico (Fig. 1); 14 from Jalisco, Nayarit 3, Michoacán 3, Zacatecas 3, Colima 2, Guanajuato 1, and Aguascalientes 1. Most were men, and virtually all, except one, were born and at least lived his childhood in a rural area with extreme poverty, inhabiting houses with mud walls, dirt floors, some with tile roofs, cardboard, or palms. Only one 9-month-old patient was born in Guadalajara city in a private hospital, with neonatal exchange transfusion antecedent, living in a house with all urban services, excluding other ways of disease transmission, for which transfusion transmission was suspected. All patients with CC recognized the insect vector, except the parents of the infants with suspected transfusion. Table 1 summarizes the clinical features of this group.

As we can see in Table 2, most seropositive patients $(96.3 \%)$ requested medical attention for clinical data of congestive heart failure Class III or IV of the New York Heart Association classification and only one for palpitations, this patient was the only one in which apical aneurysm was documented, in the other patients, left ventricular dilatation was observed with global and segmental wall hypokinesia of the left ventricle, mainly in the inferior and inferolateral region (70.3\%), in this table, we can also observe the ejection fraction, which was less than $40 \%$ in all cases. All seropositive cases had some cardiac rhythm disturbances or cardiac 
Table 1. Baseline characteristics of study participants

\begin{tabular}{|c|c|c|c|}
\hline Characteristics & $\begin{array}{c}\text { Seropositive } \\
n=27(\%)\end{array}$ & $\begin{array}{c}\text { Seronegative } \\
n=360(\%)\end{array}$ & $\begin{array}{c}\mathbf{p} \\
\text { value }\end{array}$ \\
\hline Age $\pm S D$ (years) & $60.5 \pm 5.1$ & $57.9 \pm 9.6$ & NS \\
\hline Female & $11(40.7)$ & $158(43.8)$ & NS \\
\hline \multicolumn{4}{|l|}{ History } \\
\hline Born in rural area & $26(96.2)$ & $117(32.5)$ & 0.0001 \\
\hline Recognizes vector & $26(96.2)$ & $121(33.6)$ & 0.0001 \\
\hline Suspected primoinfection & $2(7.4)$ & 0 & NS \\
\hline Recognizes vector sting & $1(3.7)$ & $3(0.83)$ & NS \\
\hline \multicolumn{4}{|l|}{ Clinical manifestations } \\
\hline Heart failure & $26(96.2)$ & $305(84.7)$ & NS \\
\hline Palpitations & $1(3.7)$ & 55 (15.2) & 0.0001 \\
\hline \multicolumn{4}{|l|}{ Image Studies } \\
\hline CTR: average \pm SD & $62.6 \pm 6.3$ & $59 \pm 3.5$ & NS \\
\hline$E F(E c h o):$ average $\pm S D$ & $28.4 \pm 6.2$ & $29.9 \pm 4.4$ & NS \\
\hline \multicolumn{4}{|l|}{ Electrocardiogram } \\
\hline Atrial fibrillation & $3(11.1)$ & $46(12.7)$ & NS \\
\hline LBBB & 0 & $70(19.4)$ & NS \\
\hline LAFB & $5(18.5)$ & $99(27.5)$ & NS \\
\hline RBBB & $7(25.9)$ & $24(6.6)$ & 0.001 \\
\hline RBBB+LAFB & $6(22.2)$ & $1(0.27)$ & 0.0001 \\
\hline AVB I & 1 (3.7) & $10(2.7)$ & NS \\
\hline AVB II & $1(3.7)$ & $14(3.8)$ & \\
\hline AVB III & 0 & $4(1.1)$ & NS \\
\hline NSVT & $4(14.8)$ & $31(8.6)$ & NS \\
\hline
\end{tabular}

AVB: atrioventricular block; CTR: cardiothoracic ratio; Echo: echocardiogram; EF: ejection fraction; LAFB: left anterior fascicular block; LBBB: left bundle branch block; NS: not significant; NSVT: non-sustained ventricular tachycardia; RBBB: right bundle branch block; SD: standard deviation.

conduction disturbances. Figure 2 describes only the electrocardiographic ventricular conduction defects; most frequent was the right bundle branch block, followed by left anterior fascicular block and association of both abnormalities, these alterations representing $66 \%$ of ventricular conduction defects. Just a few more than $10 \%$ had atrial fibrillation, atrioventricular block was found too. Premature ventricular contractions were present in $100 \%$ of the cases, in $51.8 \%$ were multifocal, and in $66.6 \%$ were two consecutive beats (couplets). Non-sustained ventricular tachycardia was documented in $14.8 \%$ of the cases. Bradycardia-tachycardia syndrome was not detected. No dilation of the digestive tract was found in any of the patients with $\mathrm{CC}$.

Two patients were in the acute phase, one of them, the infant with a history of exchange transfusion previously described, the other case was a male of 42 years with a history of alcoholism, previously asymptomatic, which received several bites by Triatoma when was drunk and unconscious in a grain warehouse; 3 weeks later, he began with progressive dyspnea and ankle edema, at that moment the echocardiogram revealed dilated cardiomyopathy with an ejection fraction $<30 \%$,
Table 2. Clinical and echocardiographic characteristics of seropositive cases

\section{Age (year) NYHA LVEF (\%) Main affected region}

\begin{tabular}{|c|c|c|c|}
\hline 70 & III & 25 & inferior, inf-lat \\
\hline 65 & IV & 29 & inferior, Inf-lat \\
\hline $9 \mathrm{~m}$ & III & 35 & anterior, ant-sep, ant-lat \\
\hline 68 & III & 39 & inferior, inf-lat, inf-sep \\
\hline 42 & III & 26 & anterior, ant-sep, inf-sep \\
\hline 68 & IV & 31 & anterior, ant-sep, inf-sep \\
\hline 56 & III & 39 & inferior, inf-lat \\
\hline 55 & III & 38 & anterior, ant-sep, inf-sep \\
\hline 86 & IV & 30 & inferior, inf-lat \\
\hline 65 & III & 29 & inferior, inf-lat \\
\hline 65 & IV & 27 & anterior, ant-sep, inf-sep \\
\hline 53 & IV & 25 & inferior, inf-lat \\
\hline 63 & IV & 25 & inferior, inf-lat, inf-sep \\
\hline 73 & IV & 38 & inferior, inf-lat \\
\hline 56 & IV & 18 & inferior, inf-lat, ant-lat \\
\hline 40 & 1 & 34 & inferior with apical aneurism \\
\hline 69 & IV & 20 & anterior, ant-sep, ant-lat \\
\hline 78 & III & 28 & inferior, inf-lat \\
\hline 65 & III & 30 & inferior, inf-lat-inf-sep \\
\hline 61 & IV & 20 & inferior, inf-lat \\
\hline 65 & IV & 19 & anterior, ant-sep, \\
\hline 60 & IV & 22 & inferior, inf-lat \\
\hline 50 & IV & 20 & inferior, inf-lat, inf-sep \\
\hline 68 & III & 32 & inferior, inf-lat \\
\hline 63 & III & 35 & inferior, inf-lat \\
\hline 59 & III & 28 & anterior, ant-lat \\
\hline 72 & IV & 25 & inferior, inf-lat, \\
\hline
\end{tabular}

ant-lat: anterolateral; ant-sep: anteroseptal; inf-lat: inferolateral; inf-sep: inferoseptal; LVEF: left ventricle ejection fraction; m: months; NYHA: New York Heart Association; class; yr: years.

after 1 week, he was hospitalized with manifestations of heart failure, a new echocardiogram showed the same data from the initial study, 5 days later pneumonia is added to the clinical evolution and dies 2 weeks after hospitalization for congestive heart failure refractory to medical treatment with multiorgan dysfunction syndrome, he also with circulating trypanosomes in blood 


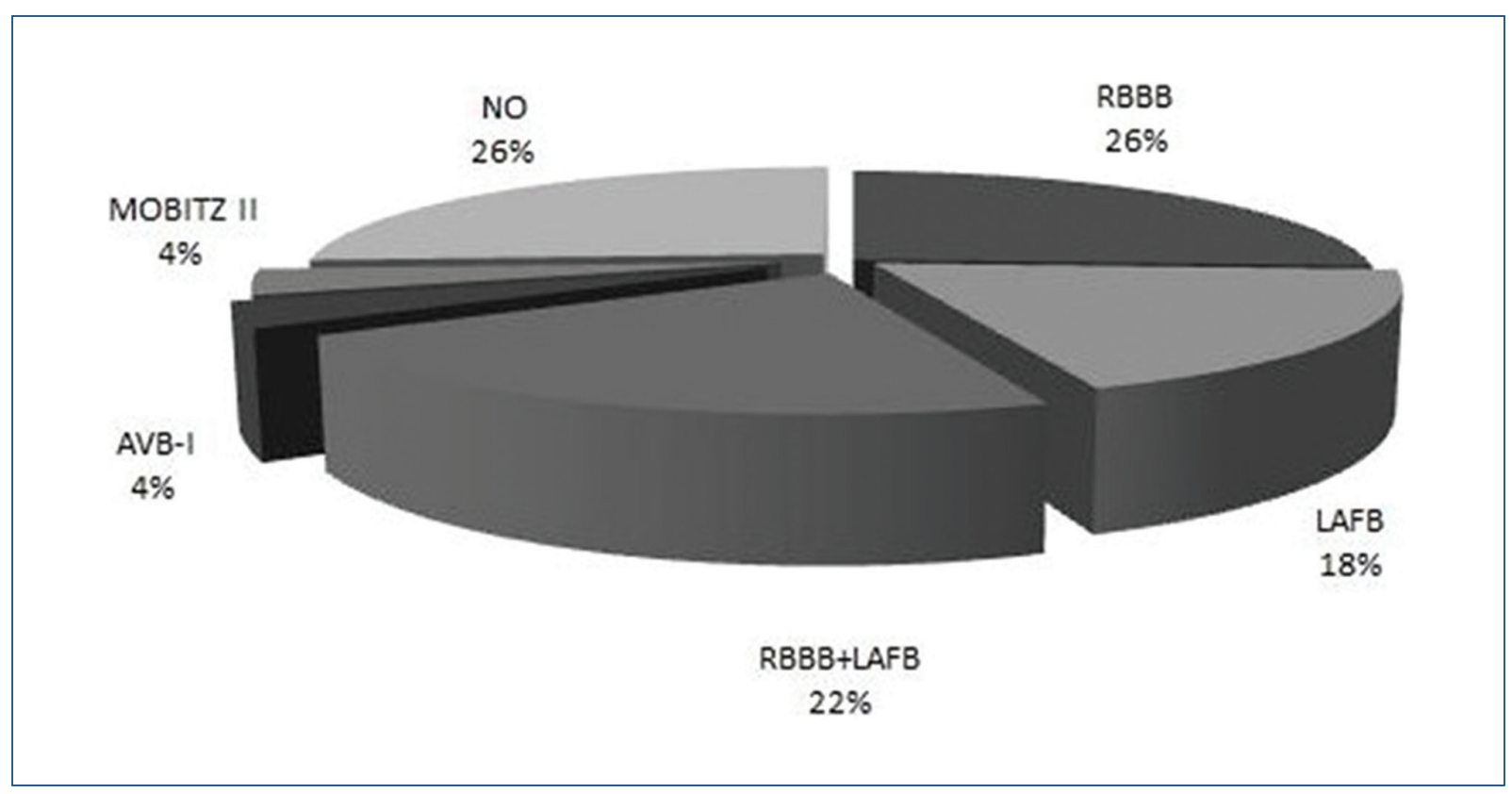

Figure 2. Here, we can observe only the ventricular conduction defects in seropositive patients, which correspond to those reported previously by other investigators. AVB-I; first-degree atrioventricular block, LAFB: left anterior fascicular block, NO: no conduction ventricular defects, RBBB: right bundle branch block.

detected with Strout method. In both acute cases, nifurtimox was used, provided by the Ministry of Health. In the case of the infant in the acute phase, parasitemia disappeared 3 weeks after starting treatment and she was discharged due to clinical improvement with treatment based on digitalis, diuretics, and angiotensin-converting-enzyme inhibitors, in a clinical follow-up, total CC regression was documented 2 years after, with normal dimensions and mobility of the left ventricle and ejection fraction greater than $60 \%$, as well as, normal physical development and growth, with negative serology throughout 9-year follow-up.

\section{Discussion}

Chagas disease is considered by different international organizations as one of the main neglected tropical diseases worldwide due to lack of attention, detection, control, and treatment ${ }^{16}$. In Mexico, even when the disease was described in 1940, the first cases of CC were reported 25 years later ${ }^{6}$. This fact could be explained if we consider that at that time, the laboratory methods for the diagnosis of disease were not sufficiently accessible in the country; furthermore, there was a strong belief that the disease was confined exclusively to South America, mainly to Brazil and
Argentina, so it was not interesting to Mexican clinicians. However, even today, the recognition of the Chagas disease is uncommon, probably due to lack of interest, ignorance of the disease, or lack of knowledge of laboratory methods to make the diagnosis. In 1991 the Southern Cone Initiative was created to combat the transmission of Chagas disease in those countries with excellent results. Mexico was included in the initiative of the countries of Central America that started in 1998. Nevertheless, Chagas disease continues to be understudied and poorly controlled in Mexico ${ }^{17,18}$. However, the Mexican government initiated actions to combat the transmission of the disease in $2013^{19}$.

Worldwide, the disease has important public health implications since although classic vector transmission only occurs in endemic countries and even in some places in the southern United States ${ }^{20}$, the less common routes of transmission, such as transfusion, congenital, and transplant-associated routes, have already been widely demonstrated in Europe ${ }^{21}$. It has been recognized that in practically the entire European continent disease is widespread given the significant number of Latin American immigrants that this continent has received in recent decades and it has also been estimated that the country with the highest number of cases with positive serology to T. cruzi is Spain ${ }^{22}$. A 
meta-analysis of European study that in aggregate screened 10,000 Latin American immigrants found a positive serological test prevalence of $4.2 \%{ }^{23}$. It was estimated that approximately 300,000 individuals with T. cruzi infection live in the United States, with 30,000 to 45,000 cardiomyopathy cases and 63 to 315 congenital infections annually ${ }^{24}$.

It is known that the prevalence of CC in cases of CD varies according to the geographical region analyzed, South America is considered to have the highest prevalence. Recently, in Los Angeles, California, in a prospective study from May 2007 to October 2011, a prevalence of $19 \%$ was reported in 135 Latin American immigrants with non-ischemic DC. Seventy-one were from Mexico and in 6 (8.4\%), CC was the etiological cause of non-ischemic $C D^{25}$. In a similar investigation conducted in New York City from July 2009 to December 2011, CC was found in 5 of 39 cases with non-ischemic DC (13\%), the patients included with dilated cardiomyopathy came from Argentina, Bolivia, Brazil, Chile, Colombia, Ecuador, El Salvador, Honduras, Mexico, Peru, Paraguay, and Venezuela, but of the five positives patients with Chagas heart disease, none came from Mexico ${ }^{26}$.

Two relevant studies in Mexico analyze the prevalence of CC on CD. One of them was carried out from 1977 to 1988 at the national institute of cardiology Ignacio Chávez, a heart disease center in Mexico City, where a prevalence of $8 \%$ was found ${ }^{9}$, this was a retrospective study, the other one was performed in the same heart disease center, in a prospective study from 1993 to 2003 , with a prevalence of $40 \%$, in this study the population was from central and southeastern states of the country ${ }^{10}$. However, in studies with small samples and short analysis periods, surprisingly high prevalence is found, which reach $82.5 \%$, these reports correspond mainly to rural populations with extreme poverty in the southeast of Mexico ${ }^{27-29}$.

We performed a prospective study for 25 years in a population of western Mexico in a general reference hospital, we found a prevalence of CC of $6.9 \%$ in patients with non-ischemic DC; according to our knowledge, this corresponds to the longest analysis time for this type of research, covering a wide geographical area from the west of the country and analyzing a significant number of DC cases.

Chagas disease has three stages: the acute phase, which usually goes unnoticed by the vast majority of patients as it is practically asymptomatic, and usually occurs in childhood or adolescence and mortality is rare, but about $5-10 \%$ of symptomatic patients without treatment die during this phase due to encephalomyelitis or severe cardiac failure ${ }^{30}$. The following is a chronic stage known as the indeterminate phase, in which the patient has no cardiological or electrocardiographic disorders or digestive tract lesions. Not all patients with positive anti-Trypanosoma antibodies develop chagasic heart disease, this is frequent in the indeterminate phase or as it is currently called; without demonstrable pathology, and just around $30 \%$ will progress to the final stage in which the digestive tract and heart dilatations are found. In our study, only two cases correspond to the acute phase, one of them died due to heart failure refractory to medical treatment and complicated with pneumonia and multiple organ failure, we ruled out septic cardiomyopathy as the cause because he was already admitted with heart failure, with dilated cardiomyopathy and 30\% ejection fraction; the other one had regression of the DC with antiparasitic treatment. The rest of the cases were found in the chronic symptomatic phase, it has been estimated that this last stage can begin 10-30 years after the onset of the disease ${ }^{31}$.

The diagnosis of CC must be made employing three criteria; epidemiological background, cardiological involvement, and laboratory confirmation. Epidemiologically, only one case did not correspond to vector transmission in this study, the infant in the acute phase with suspected transfusion transmission; in Mexico, this way of transmission has not been considered as a real public health problem; however, it has attracted the attention of a large number of researchers and its potential as a source of infection has been demonstrated ${ }^{32}$. In the last decades, the increasing immigration of Latin American population to North America and Europe has favored the spread of disease in these countries ${ }^{11}$.

We did not find dilation of the digestive tract in these patients; in Mexico, this has been a relatively rare finding $^{33}$, and it has been shown that the prevalence of gastrointestinal involvement varies according to the geographical area studied too, probably as a consequence of the different subspecific variations or strains of $T$. cruzi in each region ${ }^{30}$. Gastrointestinal involvement occurs due to the progressive destruction of intramural neurons and mainly affects the colon and esophagus, causing the typical megaesophagus that can be clinically and manometrically identical to idiopathic achalasia ${ }^{34}$.

Ventricular conduction disorders are common manifestations in the CC and they translate deterioration of left ventricular systolic function and complex ventricular arrhythmias, these incorporate high morbidity and mortality. It has been shown that ventricular conduction disorders most frequently found in $\mathrm{CC}$ are the right 
bundle branch block, followed by left anterior fascicular block and the association of both abnormalities ${ }^{35,36}$. We found the same electrocardiographic findings in $66 \%$ of patients with Chagas heart disease. Complex ventricular arrhythmias, mainly non-sustained ventricular tachycardia, represent a high risk for the development of sudden death in $\mathrm{CC}^{37}$, increasing the cost of a treatment since this can even lead to the application of an implantable cardioverter defibrillator ${ }^{38}$. We found complex ventricular ectopy in most patients and non-sustained ventricular tachycardia in $14.8 \%$ of cases, one of them was the only patient in our series with left ventricular apical aneurysm and palpitations was the solitary clinical manifestation.

Cure in Chagas heart disease is a controversial aspect; in our opinion, the infant of this study in the acute phase with suspected transfusion transmission is one of the rare cases who would meet clinical and laboratory criteria to talk about the cure of the disease ${ }^{39,40}$. The BENEFIT trial (Benznidazole Evaluation for Interrupting Trypanosomiasis), a large, multinational, multicenter, and randomized controlled trial, it has recently been shown that when the disease is found in the chronic stage, the use of antiparasitic drugs does not modify the course of the cardiological affectation ${ }^{41,42}$; however, it should be considered in cases of reinfection and when parasitemia is demonstrated, meanwhile, the campaigns to eradicate the domiciliary vector, the early diagnosis and the application of the antiparasitic treatment in the acute phase, is until now the fundamental weapon to avoid the irreversible cardiological and digestive complications, In some South American countries, very important steps have already been taken to control and eradicate this deadly disease.

\section{Conclusions}

This observational study confirms that CC is common in Mexico and could suggest a lower prevalence in western Mexico than in the south. The disease is likely underestimated due to a lack of knowledge or laboratory methods to make the diagnosis by the clinician, besides the lack of efficient campaigns for the detection and eradication of the problem. The main route of transmission of disease in our country is undoubtedly the same one that is recognized throughout Latin America, that is, through the triatomine vector insect; however, the disease should also be suspected in patients with DC who have received a blood transfusion. The take-home message from this research is that in all patients with DC, the disease should be suspected, especially when epidemiological criteria are met. It is necessary to perform research at a national level to define the true magnitude of the problem and to redesign specific campaigns to attack the problem from its origin. Chagas disease is curable if treatment is initiated early after infection.

\section{Limitations}

The main limitation of our study refers to the fact that it was carried out in a tertiary hospital and this favors that the data obtained be from the patients who attended or were referred to our institution. We should design a campaign in search of these patients with $D C$ in the primary care centers of each community in western Mexico to know the true prevalence in this geographical area of our country.

\section{Conflicts of interest}

The authors report no competing interest.

\section{Funding}

None.

\section{Ethical disclosures}

Protection of human and animal subjects. The authors declare that no experiments were performed on humans or animals for this study.

Confidentiality of data. The authors declare that they have followed the protocols of their work center on the publication of patient data.

Right to privacy and informed consent. The authors declare that no patient data appear in this article.

\section{References}

1. Chagas disease in Latin America: an epidemiological update based on 2010 estimates. Wkly Epidemiol Rec. 2015;90:33-44.

2. Ramsey JM, Peterson AT, Carmona-Castro O, Moo-Llanes DA, Nakazawa $\mathrm{Y}$, Butrick M, et al. Atlas of Mexican Triatominae (Reduviidae: Hemiptera) and vector transmission of Chagas disease. Mem Inst Oswaldo Cruz. 2015;110:339-52.

3. Salazar-Schettino PM, Bucio-Torres MI, Cabrera-Bravo M, Alba-Alvarado MC, Castillo-Saldaña DR, Zenteno-Galindo EA, et al. Enfermedad de Chagas en México. Rev Fac Med. 2016;59:6-16.

4. Coura JR. The main sceneries of Chagas disease transmission. The vectors, blood and oral transmissions-a comprehensive review. Mem Inst Oswaldo Cruz. 2015;110:277-82.

5. Mazzotti L. Dos casos de enfermedad de Chagas en el estado de Oaxaca. Gac Med Mex. 1940;70:417-20.

6. Biagi FF, Arce-Gomez E. Los dos primeros casos de miocarditis chagásica, comprobados en México. Arch Inst Cardiol Mex. 1965;35:611-9.

7. Velasco-Castrejón O, Valdespino JL, Tapia-Conyer R, Salvatierra B, Guzmán-Bracho C, Magos C, et al. Seroepidemiologia de la enfermedad de Chagas en México. Salud Pública Méx. 1992;34:186-96. 


\section{H. González-Zambrano, et al.: Chagas heart disease prevalence}

8. Bern C. Chagas' disease. N Engl J Med. 2015;373:456-66.

9. Gloss G, Barrera MR, Monteón VM, Reyes PA. Tripanosomiasis americana y cardiopatia chagásica crónica en el instituto nacional de cardiología Ignacio Chávez. Arch Inst Cardiol Mex. 1990:60:261-6.

10. Sierra-Johnson J, Olivera-Mar A, Monteón-Padilla VM, Reyes PA, Vallejo M. Epidemiological and clinical outlook of chronic Chagas' heart disease in Mexico. Rev Saúde Publica. 2005:39:754-60.

11. Angheben A, Boix L, Buonfrate D, Gobbi F, Bisoffi Z, Pupella S, et al Chagas disease and transfusion medicine: a perspective from non-endemic countries. Blood Transfus. 2015;13:540-50.

12. Martinez F, Perna E, Perrone SV, Liprandi AS. Chagas disease and heart failure: an expanding issue worldwide. Eur Cardiol. 2019;14:82-8.

13. Strout RG. A method for concentrating hemoflagellates. J Parasitol. 1962;48:100

14. WHO Expert Committee. Control of Chagas disease. World Health Organ Tech Rep Ser. 2002;905:1-109.

15. Bern C, Montgomery SP, Herwaldt BL, Rassi A Jr., Marin-Neto JA, Dantas RO, et al. Evaluation and treatment of Chagas disease in the United States: a systematic review. JAMA. 2007;298:2171-81.

16. Hotez PJ, Molyneux DH, Fenwick A, Kumaresan J, Sachs SE, Sachs JD, et al. Control of neglected tropical diseases. N Engl J Med 2007;357:1018-27.

17. Shelly EM, Acuna-Soto R, Ernst KC, Sterling CR, Brown HE. A critical assessment of officially reported Chagas disease surveillance data in Mexico. Public Health Rep. 2016;131:59-66.

18. Attaran A. Chagas' disease in Mexico. Lancet. 2006;368:1768

19. Rojo-Medina J, Ruiz-Matus C, Salazar-Schettino PM, González-Roldan JE. Enfermedad de Chagas en México. Gac Med Mex. 2018;154:605-12.

20. Garcia M, Woc-Colburn L, Aguilar D, Hotez P, Murray K. Historical perspectives on the epidemiology of human Chagas disease in Texas and recommendations for enhanced understanding of clinical Chagas disease in the Southern United States. PLoS Negl Trop Dis. 2015;9:e0003981.

21. Requena-Méndez A, Albajar-Viñas $P$, Angheben A, Chiodini $P$, Gascón J, Muñoz J. Health policies to control Chagas disease transmission in European countries. PLoS Negl Trop Dis. 2014;8:e3245.

22. Guerri-Guttenberg RA, Grana DR, Ambrosio G, Milei J. Chagas cardiomyopathy: Europe is not spared! Eur Heart J. 2008;29:2587-91.

23. Requena-Méndez A, Aldasoro E, De Lazzari E, Sicuri E, Brown M, Moore DA, et al. Prevalence of Chagas disease in Latin-American migrants living in Europe: a systematic review and meta-analysis. PLoS Negl Trop Dis. 2015;9:e0003540.

24. Bern C, Montgomery SP. An estimate of the burden of Chagas disease in the United States. Clin Infect Dis. 2009;49:e52-4.

25. Traina MI, Sanchez DR, Hernandez S, Bradfield JS, Labedi MR, Ngab TA et al. Prevalence and impact of Chagas disease among Latin American immigrants with nonischemic cardiomyopathy in Los Angeles, California. Circ Heart Fail. 2015;8:938-43.

26. Kapelusznik L, Varela D, Montgomery SP, Shah AN, Steurer FJ, Rubinstein $\mathrm{D}$, et al. Chagas disease in Latin American immigrants with dilated cardiomyopathy in New York City. Clin Infect Dis. 2013;57:e7.
27. Capps L, Abad B. Chagas cardiomyopathy and serologic testing in a small rural hospital in Chiapas, Mexico. Rev Panam Salud Publica. 2004; 15:337-40.

28. Alducin-Téllez C, Rueda-Villegas E, Medina-Yerbes I, Hernández O, López R, Peña-Hernández V, et al. Prevalence of positive serology to Trypanosoma cruzi in patients with clinical diagnosis of dilated myocardiopathy in the state of Campeche. Arch Cardiol Mex. 2011;81:204-7.

29. Cordero Pérez LJ, Zárate Castañeda R, Ramos Corrales MA, Cordero Contreras J. Miocardiopatía dilatada chagásica en el estado de Chiapas, México. Rev Mex Cardiol. 2002;13:153-7.

30. Prata A. Clinical and epidemiological aspects of Chagas disease. Lancet Infect Dis. 2000;1:92-100.

31. Malik LH, Singh GD, Amsterdam EA. Chagas heart disease: an update. Am J Med. 2015;128:1251.

32. Kirchhoff LV, Paredes $P$, Lomelí-Guerrero A, Paredes-Espinoza M, Ron-Guerrero CS, Delgado-Mejía M, et al. Transfusion-associated Chagas disease (American trypanosomiasis) in Mexico: implications for transfusion medicine in the United States. Transfusion. 2006;46:298-304.

33. Sánchez-Guillén Mdel C, López-Colombo A, Ordóñez-Toquero G, Gomez-Albino I, Ramos-Jimenez J, Torres-Rasgado E, et al. Clinical forms of Trypanosoma cruzi infected individuals in the chronic phase of Chagas disease in Puebla, Mexico. Mem Inst Oswaldo Cruz. 2006;101:733-40.

34. Meneghelli UG, Darezzo FM, Peria FM, Almeida FH, Rodrigues CM, Aprile LR, et al. Clinical, radiographic, and manometric evolution of esophageal involvement by Chagas' disease. Dysphagia. 2005;20:40-5.

35. Ribeiro AL, Sabino EC, Marcolino MS, Salemi VM, lanni BM, Fernandes F, et al. Electrocardiographic abnormalities in Trypanosoma cruzi seropositive and seronegative former blood donors. PLoS Negl Trop Dis. 2013;7:e2078.

36. Rojas LZ, Glisic M, Pletsch-Borba L, EcheverrôÂa LE, Bramer WM, Bano A, et al. Electrocardiographic abnormalities in Chagas disease in the general population: a systematic review and meta-analysis. PLoS Negl Trop Dis. 2018;12:e0006567.

37. Barbosa MP, Carmo AA, Rocha MO, Ribeiro AL. Ventricular arrhythmias in Chagas disease. Rev Soc Bras Med Trop. 2015;48:4-10

38. Gali WL, Sarabanda AV, Baggio JM, Ferreira LG, Gomes GG, Marin-Neto JA et al. Implantable cardioverter-defibrillators for treatment of sustained ventricular arrhythmias in patients with Chagas' heart disease: comparison with a control group treated with amiodarone alone. Europace. 2014;16:674-80.

39. Rodriques Coura J, De Castro SL. A critical review on Chagas disease chemotherapy. Mem Inst Oswaldo Cruz. 2002;97:3-24.

40. De Lana M, Martins-Filho OA. Revisiting the posttherapeutic cure criterion in Chagas disease: time for new methods, more questions, doubts, and polemics or time to change old concepts? Biomed Res Int. 2015;2015:652985

41. Morillo CA, Marin-Neto JA, Avezum A, Sosa-Estani S, Rassi A Jr., Rosas $F$, et al. Randomized trial of benznidazole for chronic Chagas' cardiomyopathy. N Engl J Med. 2015;373:1295-306.

42. Rassi A Jr., Marin Neto JA, Rassi A. Chronic Chagas cardiomyopathy: a review of the main pathogenic mechanisms and the efficacy of aetiological treatment following the BENznidazole evaluation for interrupting trypanosomiasis (BENEFIT) trial. Mem Inst Oswaldo Cruz. 2017;112:224-35. 